\title{
White matter deficits assessed by diffusion tensor imaging and cognitive dysfunction in psychostimulant users with comorbid human immunodeficiency virus infection
}

Victor M. Tang ${ }^{1 \dagger}$, Donna J. Lang ${ }^{2,3 \dagger}$, Chantelle J. Giesbrecht ${ }^{4}$, William J. Panenka ${ }^{1,3}$, Taylor Willi, ${ }^{1,3}$, Ric M. Procyshyn ${ }^{1,3}$, Fidel Vila-Rodriguez ${ }^{1}$, Willough Jenkins ${ }^{1}$, Tania Lecomte ${ }^{5}$, Heidi N. Boyda ${ }^{3,6}$, Ana Aleksic ${ }^{3,6}$, G. William MacEwan', William G. Honer ${ }^{1,3}$ and Alasdair M. Barr ${ }^{3,6^{*}}$

\begin{abstract}
Background: Psychostimulant drug use is commonly associated with drug-related infection, including the human immunodeficiency virus (HIV). Both psychostimulant use and HIV infection are known to damage brain white matter and impair cognition. To date, no study has examined white matter integrity using magnetic resonance imaging (MRI) diffusion tensor imaging (DTI) in chronic psychostimulant users with comorbid HIV infection, and determined the relationship of white matter integrity to cognitive function.

Methods: Twenty-one subjects (mean age $37.5 \pm 9.0$ years) with a history of heavy psychostimulant use and HIV infection ( $8.7 \pm 4.3$ years) and 22 matched controls were scanned on a 3T MRI. Fractional anisotropy (FA) values were calculated with DTI software. Four regions of interest were manually segmented, including the genu of the corpus callosum, left and right anterior limbs of the internal capsule, and the anterior commissure. Subjects also completed a neurocognitive battery and questionnaires about physical and mental health.
\end{abstract}

Results: The psychostimulant using, HIV positive group displayed decreased white matter integrity, with significantly lower FA values for all white matter tracts $(p<0.05)$. This group also exhibited decreased cognitive performance on tasks that assessed cognitive set-shifting, fine motor speed and verbal memory. FA values for the white matter tracts correlated with cognitive performance on many of the neurocognitive tests.

Conclusions: White matter integrity was thus impaired in subjects with psychostimulant use and comorbid HIV infection, which predicted worsened cognitive performance on a range of tests. Further study on this medical comorbidity is required.

Keywords: Comorbidity, Diffusion tensor imaging, Human immunodeficiency virus, Magnetic resonance imaging, Neurocognitive, Psychostimulant

\footnotetext{
*Correspondence: al.barr@ubc.ca

†Victor M. Tang and Donna J. Lang contributed equally to this work

${ }^{6}$ Department of Pharmacology, University of British Columbia, 2176

Health Sciences Mall, Vancouver, BC V6T1Z3, Canada

Full list of author information is available at the end of the article
} 


\section{Background}

Illicit drug use represents a pervasive public health concern, creating substantial cost and burden for individuals and society. Psychostimulant drugs, including cocaine, amphetamines and methamphetamine are among the most commonly used substances worldwide [1]. Concern about the widespread use of psychostimulants includes the health risks associated with chronic substance use [2,3].

Research with magnetic resonance imaging (MRI) has helped to elucidate the deleterious effects of psychostimulant use on brain structure, with consistent abnormalities being found within fronto-striatal systems [4]. Diffusion tensor imaging (DTI) has been used to examine the effects of psychostimulant use on the white matter tracts of the brain. DTI measures the directional coherence of the diffusion of water in tissue. A reduction in anisotropy indicates reduced organization or integrity of white matter, usually as a result of axonal compromise, or increased membrane permeability (e.g. demyelination) [5]. The most common method for quantifying anisotropy is through fractional anisotropy (FA). Researchers have reported decreased FA in frontal white matter in methamphetamine users $[6,7]$ and in frontal white matter and the corpus callosum of cocaine users $[8,9]$ (Table 1). Decreases have also been found in major white matter tracts connecting the right and left hemispheres, with decreased FA in the genu of the corpus callosum associated with methamphetamine use $[10,11]$ and cocaine use $[9,12]$.

When studying the effects of drug use on the brain, it is also important to consider the clinically complex issue of comorbidity that is common in many psychostimulant users. The incidence of infectious disease in psychostimulant users is high, including the human immunodeficiency virus (HIV) [13] that may be acquired by intravenous drug use and unsafe sexual practices [14]. In HIV/AIDS affected individuals who are not psychostimulant abusers, several brain regions have been shown to exhibit decreased FA values [15-18] (Table 2). White matter changes are related to duration of infection, and are more affected in those with cognitive deficits [19]. Cognitive impairment is seen in as much as $63 \%$ of this population [20] and such deficits correlate with FA value decreases [21-23].

In the present study, our goal was to examine the neuroanatomical and cognitive changes in psychostimulant users with comorbid HIV infection, using DTI. To our knowledge, there has not been a study of FA values in this comorbid population, even though there known effects of psychostimulant use and HIV on white matter integrity. We have recently reported that comorbid addiction and infectious disease can significantly impact factors such as everyday functioning $[24,25]$. In the present study, we have focused specifically on the key frontotemporal white matter pathways of the genu of the corpus callosum, the right and left anterior limbs of the internal capsule, and the anterior commissure. It has been proposed that forebrain regions that are connected by these tracts are most affected by psychostimulant use, as they receive dopamine projections from the midbrain, which are a key substrate of the toxic effects of psychostimulant exposure [2], and are important for neurocognitive function. Participants were also subject to a comprehensive neuropsychological test battery in order to assess function in multiple cognitive domains.

\section{Methods \\ Participants}

Twenty-one HIV-positive subjects seeking care for psychostimulant use (the "patient" group) were recruited from St. Paul's and Vancouver General Hospital in Vancouver, Canada. Referrals were through staff clinicians in the emergency department. Patients were $\geq 19$ years old, had a history of psychostimulant exposure, HIV-positive and could provide informed consent. Twenty-two age, gender and premorbid IQ matched controls were recruited from the same geographical community. All subjects in the study provided written consent. The study was approved by the UBC Clinical Research Ethics Board (CREB), in accordance with Canadian tri-council guidelines and the Declaration of Helsinki. Exclusion criteria included: surgery in previous 6 months, pregnancy, metal implants, claustrophobia, uncorrectable visual impairment and IQ $<70$.

\section{MRI acquisition}

A 3Tesla MRI (Philips System) with an eight channel head coil was used. A T1-weighted 3D fast spoiled gradient echo (SPGR) inversion recovery prepped series for volumetric assessment was performed for region of interest (ROI) seeding in structural space in the transverse plane with: $\mathrm{TR}=7.7 \mathrm{~ms}$, $\mathrm{TE}=3.6 \mathrm{~ms}$, flip angle $=8^{\circ}, \mathrm{FOV}=256 \times 170 \times 200 \mathrm{~mm}$, acquisition and reconstruction matrices $=256 \times 256,170$ slices, slice thickness $=1 \mathrm{~mm}$, gap $=0,1 \mathrm{~mm}$ isotropic voxel, SENSE $=0$. DTI images were acquired in the transverse plane with $\mathrm{TR}=7500 \mathrm{~ms}, \mathrm{TE}=54 \mathrm{~ms}$, b-value $=800,16$ directions, flip angle $=90^{\circ}$, acquisition matrix $=112 \times 112$, reconstruction matrix $=110 \times 110$, voxel dimensions $=0.875 \mathrm{~mm} \times 0.875 \mathrm{~mm} \times 2$, FOV $=224 \times 144 \times 224 \mathrm{~mm}, 72$ slices, slice thickness $=2 \mathrm{~mm}$, gap $=0$, SENSE $=1$.

\section{ROI manual segmentation}

The rostrum and genu of the corpus callosum, the right and left anterior limb of the internal capsule, and the 


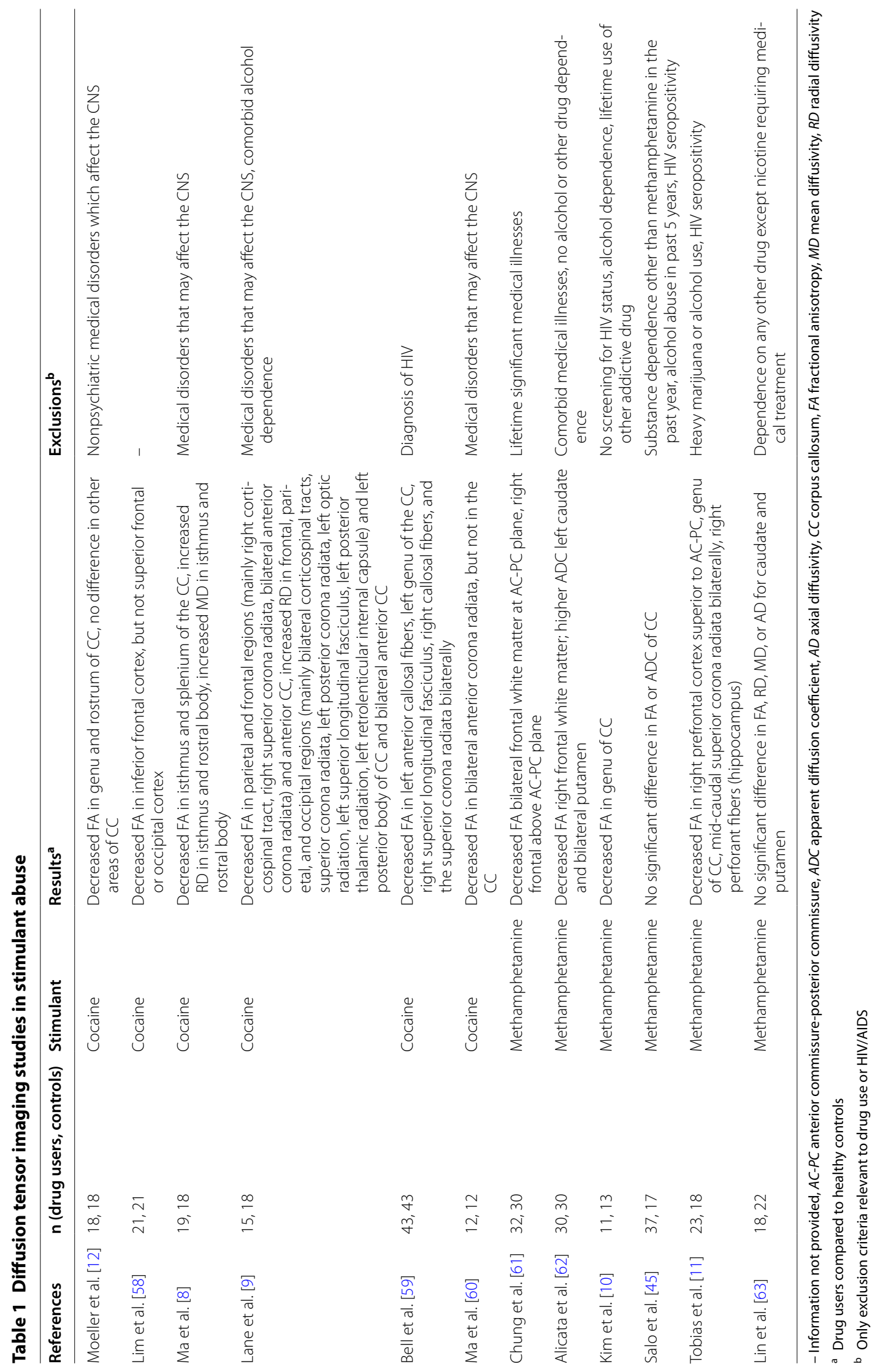




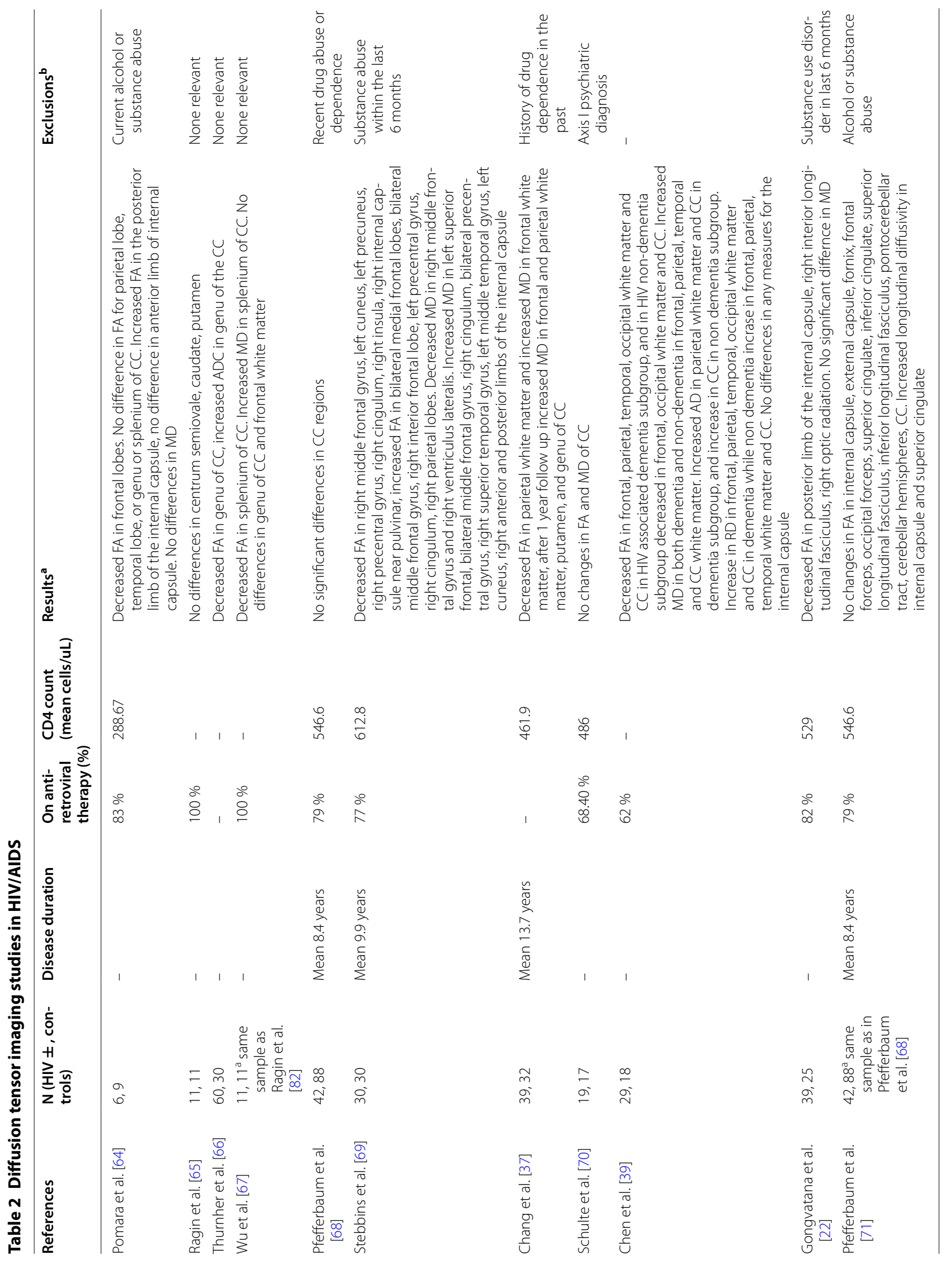




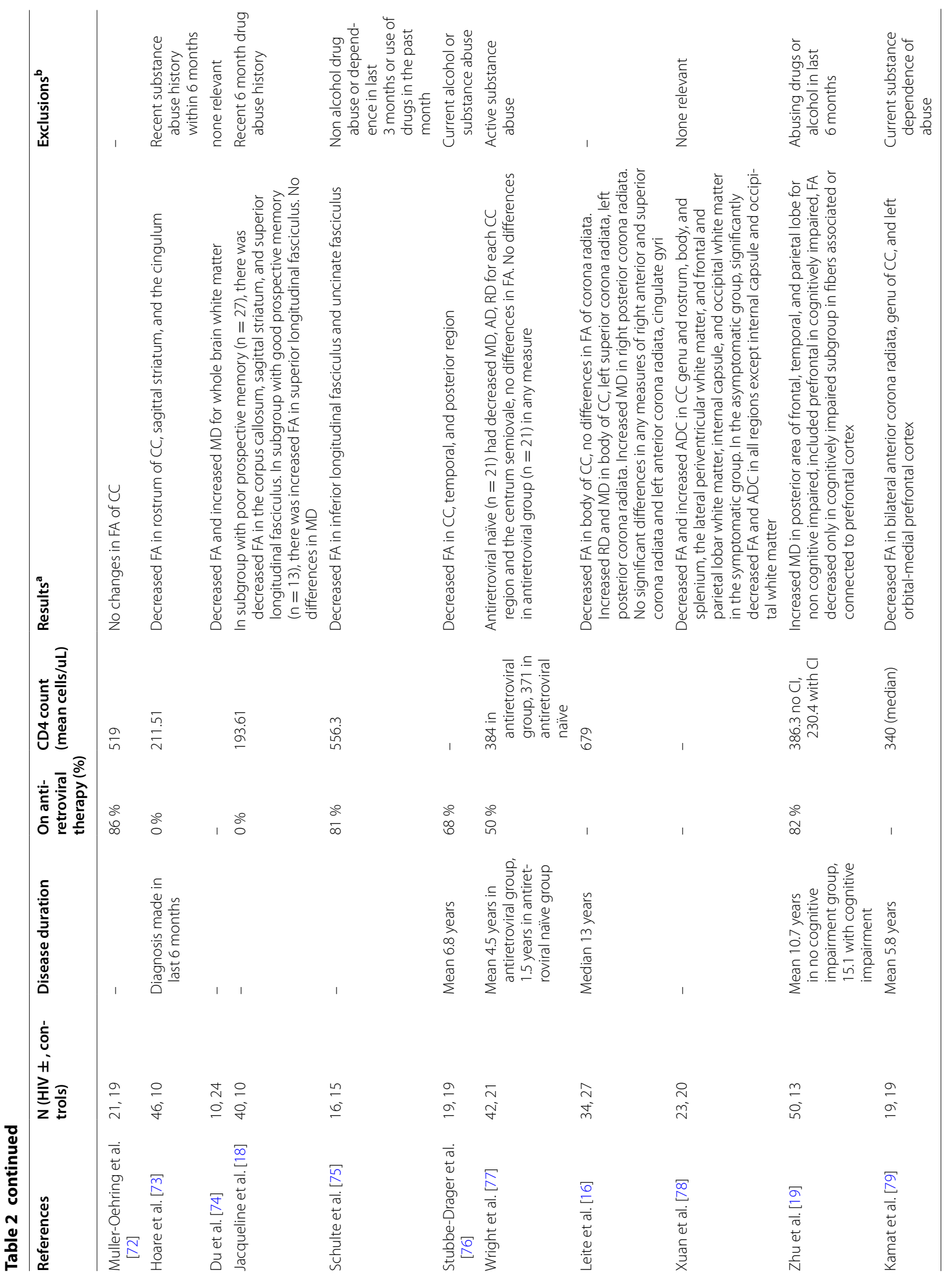




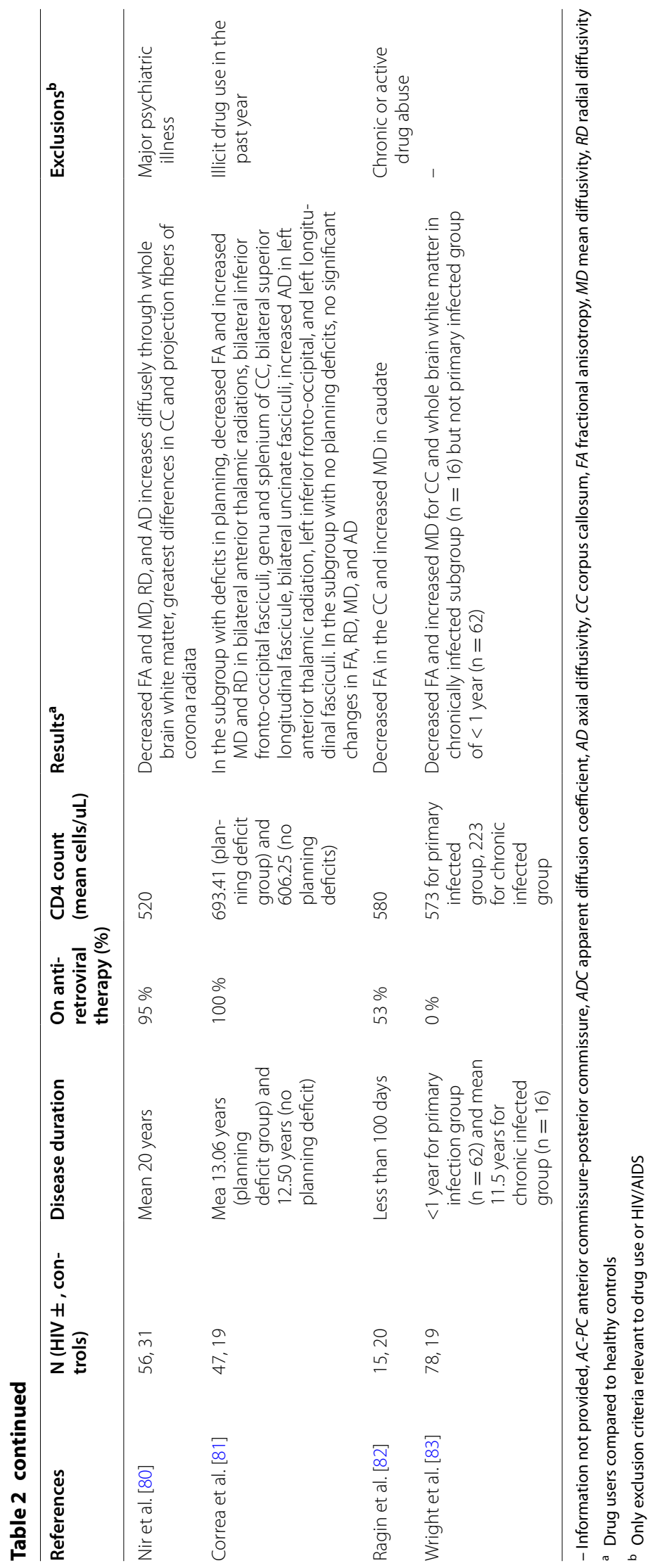


anterior commissure were manually segmented on the T1-SPGR structural scans using the interactive masking tool from FMRIB Software Library 4.1. The anterior limb of the internal capsule was well visualized as a visible white matter tract bounded medially by the caudate and laterally by the putamen on the axial plane, seven slices superior to the first visualization of the anterior commissure.

The anterior commissure was manually segmented axially. The analysis of this ROI was restricted to fibers that crossed two geometrically placed ROIs $4 \mathrm{~mm}$ lateral on each side of a mid-sagittal line drawn in the coronal plane. Borders of the corpus callosum genu were traced on the mid-sagittal slice in the sagittal plane. The posterior border was defined with a vertical line marked by the anterior-most point of the inner convexity of the anterior callosum. To remove extraneous fibers and restrict analysis to fronto-temporal connections, additional ROIs from automatically segmented masks were applied to restrict fiber analysis to target tracts. For the genu, all other regions of the corpus callosum were excluded, as well as the fornix. An occipital lobe mask excluded fibers to the corpus callosum genu, anterior limb of the internal capsule, and anterior commissure. Intra-rater reliabilities for FA values for all ROIs. Manual ROI selection was repeated on a random set of five controls and five patients for each tract. Intra-class correlation coefficients were $0.83-0.96$ for all tracts.

\section{Image processing}

Image processing was performed on an AppleMacPro Tower Quad Core Intel computer, OS X version 10.5.8. Raw images were converted to NIFTI format with MICRON dcm2nii shareware. Processing of diffusion weighted data for VBM-style analysis, specifically motion and standard eddy current distortion correction as recommended by FSL (see FRMRIB-FDT v2.0 pipeline), local modeling of diffusion parameters, spatial registration, tractography and local fitting of diffusion tensors was performed with FMRIB Diffusion Toolbox as part of the FMRIB Software Library (FSL v4.1.4 http://www. fmrib.ox.ax.uk/fsl). DTI data were registered from diffusion space to structural space and from structural space to standard (MN152) space. Prior to analysis, all diffusion scans were reconstructed to a voxel dimension of $0.88 \times 0.88 \times 2.0$ to mitigate partial volume effects. Tracts were generated from the manual ROI seeds. All tracts were subsequently normalized by seed size. The minimum probability threshold for normalized tracts was set to 0.2 to avoid over-inclusion of non-tract voxels. Volume extraction of frontal pathways from FSL was based on standardized automated reconstruction from the Bayesian framework, in which probabilistic estimation from the diffusion images is calculated based on multiple compartments of anisotropic diffusion and a single compartment of isotropic diffusion per voxel. This is expressed as the diffusion data at any given individual voxel as a function of volume and orientation of any given compartment. FSL applies automated summation of the voxel volumes associated with the manually placed tractography seed at the recommended threshold to calculate the final tract volume. One scan had to be excluded due to motion artifact. All scans were reviewed by a neuroradiologist for evidence of brain injury which could have affected DTI indices; no scans were required to be excluded from the analysis.

Volumetric segmentation was performed with Freesurfer. Processing included motion correction, removal of non-brain tissue, automated Talairach transformation, segmentation of the subcortical white matter and deep gray matter volumetric structures, intensity normalization, tessellation of the gray/white matter boundary, automated topology correction, and surface deformation via intensity gradients [26]. Maps were created using spatial intensity gradients across tissue classes and are therefore not simply reliant on absolute signal intensity.

\section{Cognition}

Before testing, subjects were asked if they were currently experiencing the effects of a drug. If they answered affirmatively, or the research assistant suspected them of having just used a drug, they were excluded from the study. Premorbid intellectual functioning was estimated from the Full Scale IQ score on the North American adult reading test (NAART). All subjects completed a comprehensive neuropsychological battery. Multiple cognitive domains were evaluated (neurocognitive tests and outcome variables listed in parentheses); including processing/visual scanning speed and cognitive set-shifting (trail making test; TMT; Trail A and B completion time), fine motor speed and dexterity (Grooved Pegboard; dominant and non-dominant hand completion time), verbal learning and memory (California verbal learning test-II; CVLT-II; total recall trials $1-5$, short delay free recall, long delay free recall, and total recognition discriminability).

The computerized Cambridge neuropsychological test automated battery (CANTAB; [27]) was used to examine sustained attention (rapid visual information processing; RVP; A' signal detection measure of sensitivity), and components of attentional set-shifting (intra/extra dimensional shift; IED; concept formation errors and concept switching errors). Failure to complete a particular stage on the IED subtest ended the task. Therefore, adjusted error scores for all non-completers were established by adding one error to the error total observed in 
the participant who made the most errors yet completed the given stage.

Score distributions were examined for normality and outliers. For several variables (e.g., Trails A and B, Grooved Pegboard, and RVP A') outliers were identified, and adjustments to these scores were made according to [28]. To control for the effects of years of education, which differed significantly between groups, unstandardized residuals were calculated by regressing raw cognitive scores for the entire sample on education. For consistency, the signs of unstandardized residuals for certain variables (e.g., errors or speed) were reversed (i.e., multiplied by -1 ) so that lower values represented worse performance.

\section{Demographics}

Subjects provided demographic information. Drug use over the previous 30 days was collected through the Maudsley Addiction Profile [29] for both the patient group and the control group. A cumulative total of days in the month spent using psychostimulant drugs was also determined, whereby each day spent using a specific psychostimulant drug was added together. A urine drug screen also was obtained for both groups which detected recent use of amphetamines, barbiturates, benzodiazepines, cocaine (including crack), marijuana, methadone, 3,4-methylenedioxymethamphetamine, opiates and tricyclic antidepressants. Confirmation of HIV status was obtained from patient medical charts. For subjects with $\mathrm{HIV}$, an additional questionnaire was administered to gather information about their illness. This is a 21 item questionnaire that includes information about time of infection, past and current treatment, related medical conditions and hospitalization. Psychiatric health was assessed with the Mini International Neuropsychiatric Interview (MINI), which is a well validated structured clinical interview that assesses lifetime mental health and substance use disorders based on Diagnostic and Statistical Manual, 4th ed. (DSM-IV) and the International Classification of Diseases (ICD)-10 criteria [30]. All subjects were offered the opportunity to complete a complete blood count $(\mathrm{CBC})$ with differential. CD4 and CD8 counts were also measured while HIV positive status was confirmed.

\section{Statistical analysis}

A Pearson Chi square $\left(\chi^{2}\right)$ analysis was performed to compare the groups on categorical demographic variables. Independent $\mathrm{t}$-tests compared mean group FA values and cognitive outcome variables for normally distributed variables. For non-normal cognitive data (TMT $B$ and the IED subtests), the non-parametric MannWhitney $U$ test was employed. T-tests were two tailed with statistical significance defined as $p<0.05$. Effect sizes (ES) for group comparisons were also computed using Cohen's $d$ (corresponding to ES of small $=0.2$, medium $=0.5$, large $=0.8$ ). Pearson correlations $(r)$ assessed associations between FA values and cognitive outcome variables. Analyses were performed using SPSS 16 software (SPSS Inc., USA).

\section{Results}

\section{Demographic variables}

The mean age of the patient group was $37.45( \pm 9.0)$ years, range $22-58$ years. The mean age of controls was 39.55 ( \pm 9.0$)$ years, range $20-57$ years. The control group included 13 males and 9 females. The patient group included 14 males and 7 females. Gender distribution did not differ between groups $(p>0.46)$. Subjects did not differ in age $(p>0.22)$ and estimated premorbid intellectual functioning on the NAART test $(p>0.16)[99.7 \pm 8.8$ (patients) vs $103.0 \pm 6.8$ (controls)]. There was a significant group difference in mean years of completed education $\left(\mathrm{t}_{(41)}=2.79 p<0.01\right)[10.29 \pm 2.63$ years (patients) vs $12.05 \pm 1.33$ years (controls)]. Details on HIV status in the patient group are listed in Table 3.

Results of the MINI indicated that 10 subjects in the patient group had a lifetime diagnosis of substanceinduced psychosis (versus no controls), 9 a history of depression (versus 5 controls), 2 a history of mania (versus no controls) and 2 a history of PTSD (versus 2 controls). All subjects in the patient group met lifetime criteria for non-alcoholic psychoactive substance use disorder, versus no controls. For bloodwork, 16 of the patient group and 17 of the controls completed the blood work. Subjects in the patient group exhibited significantly lower total white blood cell counts, as well as lower CD4 cell counts, higher CD8 cell counts, and a lower CD4:CD8 ratio (Table 4).

\section{Drug use}

Drug use over the previous 30 days is listed in Table 5 (only substances where more than one subject used the drug are included). The groups differed significantly in alcohol, heroin, cocaine powder, crack cocaine, amphetamines and cannabis use, with alcohol use higher in the

Table 3 HIV status

\begin{tabular}{ll}
\hline & Patients $(\mathbf{n}=\mathbf{2 1})$ \\
\hline Average duration of HIV infection & $8.7 \pm 4.3$ years \\
Current status HIV or AIDS & HIV 18 (86 \%), AIDS 3 (14\%) \\
Previous HIV-related hospitalizations (Y/N) & $11 \mathrm{Y}(53 \%), 10 \mathrm{~N}(47 \%)$ \\
Currently treated for HIV(Y/N) & $15 \mathrm{Y}(71 \%), 6 \mathrm{~N}(29 \%)$ \\
If not currently treated, were previously & $4 \mathrm{Y}(66 \%), 2 \mathrm{~N}(33 \%)$ \\
\hline
\end{tabular}


Table 4 Results of complete blood count and differential

\begin{tabular}{lcc}
\hline & Controls $(\mathbf{n}=\mathbf{1 7})$ & Patients $(\mathbf{n}=\mathbf{1 6})$ \\
\hline White blood cell count (giga/L) & $6.76 \pm 1.81$ & $4.93 \pm 1.61^{* *}$ \\
Helper CD4 (\%) & $45.35 \pm 5.32$ & $28.00 \pm 16.04^{* *}$ \\
Helper CD4 Absolute number & $874.11 \pm 192.32$ & $435.00 \pm 310.07^{* *}$ \\
$\quad$ per $\mu \mathrm{L})$ & & \\
Suppressor CD8 (5) & $24.53 \pm 7.53$ & $45.94 \pm 19.94^{* *}$ \\
$\begin{array}{l}\text { Suppressor CD8 Absolute } \\
\quad \text { number (per } \mu \mathrm{L})\end{array}$ & $480.59 \pm 198.82$ & $836.88 \pm 735.46$ \\
CD4:CD8 ratio & $2.04 \pm 0.71$ & $0.96 \pm 1.09^{* *}$
\end{tabular}

Numbers indicate mean score $( \pm S E M)$ for either the patient or control group. Significant difference between groups ${ }^{*} p<0.05,{ }^{* *} p<0.01$

Table 5 Substance use over prior 30 days

\begin{tabular}{|c|c|c|}
\hline & Controls $(n=22)$ & Patients $(n=21)$ \\
\hline Alcohol (\# using) & 16 & $7^{* *}$ \\
\hline Alcohol (\# days) [4.2 \pm 3.7 units] & $4.6 \pm 5.7$ & $2.4 \pm 6.5$ \\
\hline Heroin (\# using) & 0 & $7^{* *}$ \\
\hline Heroin (\# days) $[0.2 \pm 0.15 \mathrm{~g}]$ & 0 & $3.4 \pm 7.9^{*}$ \\
\hline Cocaine powder (\# using) & 2 & $13^{* *}$ \\
\hline $\begin{array}{l}\text { Cocaine powder (\# days) } \\
{[0.52 \pm 0.76 \mathrm{~g}]}\end{array}$ & 1 & $9.4 \pm 12.1^{* *}$ \\
\hline Crack cocaine (\# using) & 0 & $19^{* *}$ \\
\hline $\begin{array}{l}\text { Crack cocaine (\# days) } \\
{[0.92 \pm 1.65 \mathrm{~g}]}\end{array}$ & 0 & $18.3 \pm 12.3^{* *}$ \\
\hline Amphetamines (\# using) & 0 & $6^{* *}$ \\
\hline $\begin{array}{l}\text { Amphetamines (\# days) } \\
{[0.38 \pm 0.40 \mathrm{~g}]}\end{array}$ & 0 & $4.0 \pm 8.6^{*}$ \\
\hline Cannabis (\# using) & 4 & $13^{* *}$ \\
\hline Cannabis (\# days) [0.95 $\pm 0.68 \mathrm{~g}]$ & $1.6 \pm 5.6$ & $14.3 \pm 13.9^{* *}$ \\
\hline
\end{tabular}

Numbers indicate either number of subjects per group using the drug (\# using) or mean number of days per 30 days spent using the drug (\# days) \pm SEM.

Significant difference between groups ${ }^{*} p<0.05,{ }^{* *} p<0.01$. For number of days using each drug, mean daily intake ( \pm SEM) for both groups for cases who used the drug is included in square parentheses

controls and every other drug higher in the patient group. The most commonly used drug in the patient group was crack cocaine, followed by cocaine powder and cannabis. While only six subjects in the patient group reported using amphetamines in the previous month, all subjects in this group had used some form of psychostimulant drug (amphetamines, cocaine powder or crack cocaine) in the previous 30 days, with psychostimulants being used an average of 32 cumulative "days" per person during this period. The results of the urine drug screen correlated well with self-reported drug use, with 18 of the 21 subjects in the patient group testing positive for recent cocaine or amphetamine use (previous $48 \mathrm{~h}$ ), and only one subject in the control group testing positive for cocaine.

\section{Fractional anisotropy}

Summary FA values are shown in Table 6. Significant between-group differences in FA values were seen in the corpus callosum genu $\left(\mathrm{t}_{(40)}=3.84 p<0.001\right)$, left $\left(\mathrm{t}_{(40)}=3.23 p<0.005\right)$ and right $\left(\mathrm{t}_{(40)}=2.30 p<0.05\right)$ anterior limbs of the internal capsule, and in the anterior commissure $\left(\mathrm{t}_{(40)}=2.10 p<0.05\right)$, as FA values were lower for the patient group in all of these white matter pathways (Fig. 1). Correlational analyses did not reveal relationships between FA and age in either group for any ROI. There were also significant group differences for medial diffusivity (MD) and radial diffusivity (RD) values for all pathways other than the anterior commissure, and differences in axial diffusivity (AD) values for both the left and right anterior limb of the internal capsule pathways. Total white matter volume in the patient group was smaller than the control group, but this narrowly failed to obtain significance when co-varied for total brain volume $(\mathrm{p}=0.052)$.

\section{Neurocognitive performance}

The patient group performed worse than controls on all cognitive variables (Table 7). Group differences were seen in cognitive set-shifting (TMT B; $U=147.0$, $z=-2.04, p<0.05)$, fine motor speed and dexterity bilaterally (Grooved Pegboard; dominant hand: $\mathrm{t}_{(41)}=-3.96$, $p=0.001$; non-dominant hand: $\left.\mathrm{t}_{(41)}=-3.80, p=0.001\right)$, word list acquisition (CVLT-II total recall: $\mathrm{t}_{(41)}=-2.37$, $p<0.05)$ and immediate recall (CVLT-II short delay free recall: $\left.\mathrm{t}_{(41)}=-2.13, p<0.05\right)$.

\section{Relationship between DTI FA values and cognition}

Exploratory analyses between FA values and cognitive measures for the group as a whole revealed a number of significant associations (Table 8). For the anterior commissure, lower FA values were significantly correlated with slower fine motor speed and dexterity with the dominant hand (Grooved pegboard; $r=-0.338 ; p<0.05$ ). Lower FA values in this pathway were also associated with poorer sustained attention (RVP $\mathrm{A}^{\prime} ; r=0.364$; $p<0.005)$.

For the left anterior limb of the internal capsule, lower FA values were significantly correlated with slower fine motor speed and dexterity bilaterally (Grooved Pegboard dominant hand: $r=-0.468, p<0.005$; non-dominant hand: TMT Trail B; $r=-0.409, p<0.01$ ). Higher FA values were associated better sustained attention (RVP A'; $r=0.403, p<0.05)$. Further, higher FA values predicted better verbal learning (CVLT total recall; $r=0.419$, $p<0.01$ ) and memory, including after both short (CVLT Short Delay; $r=0.376, p=0.017$ ) and long delays (CVLT Long Delay; $r=0.416, p=0.008$ ). 
Table 6 DTI measures of white matter tracts in HIV positive patients with history of psychostimulant use

\begin{tabular}{|c|c|c|c|}
\hline & Controls $(n=22)$ & Patients $(n=20)$ & $\begin{array}{l}\text { Effect size }(d) \\
\text { and } p \text { value }\end{array}$ \\
\hline \multicolumn{4}{|c|}{ Genu of CC } \\
\hline FA & $0.3838 \pm 0.0254$ & $0.3517 \pm 0.0289$ & $1.184 ; 0.0001^{*}$ \\
\hline $\mathrm{MD}$ & $0.910 \pm 0.054$ & $0.951 \pm 0.039$ & $-0.864 ; 0.008^{*}$ \\
\hline$A D$ & $1.283 \pm 0.071$ & $1.301 \pm 0.047$ & $-0.296 ; 0.324$ \\
\hline $\mathrm{RD}$ & $0.723 \pm 0.052$ & $0.775 \pm 0.046$ & $-1.056 ; 0.002^{*}$ \\
\hline \multicolumn{4}{|c|}{ Right ALIC } \\
\hline FA & $0.3555 \pm 0.0229$ & $0.3391 \pm 0.0233$ & $0.710 ; 0.027^{*}$ \\
\hline MD & $0.907 \pm 0.064$ & $0.953 \pm 0.060$ & $-0.740 ; 0.022^{*}$ \\
\hline$A D$ & $1.245 \pm 0.071$ & $1.288 \pm 0.061$ & $-0.647 ; 0.044^{*}$ \\
\hline $\mathrm{RD}$ & $0.737 \pm 0.064$ & $0.785 \pm 0.063$ & $-0.756 ; 0.020^{*}$ \\
\hline \multicolumn{4}{|c|}{ Left ALIC } \\
\hline FA & $0.3798 \pm 0.0307$ & $0.3539 \pm 0.0190$ & $1.002 ; 0.002^{*}$ \\
\hline MD & $0.857 \pm 0.055$ & $0.914 \pm 0.042$ & $-1.157 ; 0.001^{*}$ \\
\hline$A D$ & $1.208 \pm 0.061$ & $1.254 \pm 0.049$ & $-0.827 ; 0.011^{*}$ \\
\hline $\mathrm{RD}$ & $0.681 \pm 0.058$ & $0.745 \pm 0.042$ & $-1.254 ; 0.0001^{*}$ \\
\hline \multicolumn{4}{|l|}{$A C$} \\
\hline FA & $0.3782 \pm 0.0499$ & $0.3509 \pm 0.0332$ & $0.638 ; 0.042^{*}$ \\
\hline MD & $1.107 \pm 0.189$ & $1.142 \pm 0.200$ & $-0.180 ; 0.558$ \\
\hline$A D$ & $1.539 \pm 0.187$ & $1.555 \pm 0.239$ & $-0.075 ; 0.773$ \\
\hline $\mathrm{RD}$ & $0.937 \pm 0.184$ & $0.893 \pm 0.191$ & $0.235 ; 0.455$ \\
\hline
\end{tabular}

Numbers indicate mean score ( \pm SEM) for fractional anisotropy (FA), medial diffusivity (MD), axial diffusivity (AD) and radial diffusivity (RD) values for either the patient or control group; units for $\mathrm{MD}, \mathrm{AD}$ and $\mathrm{RD}$ are $\left(\mathrm{mm}^{2} / \mathrm{s} \times 10^{-3}\right)$. Tracts include the genu of the corpus callosum (CC), left and right anterior limb of the internal capsule (ALIC) and the anterior commissure (AC). Values represent group mean $\pm S D$

* Significant difference between groups $p<0.05$
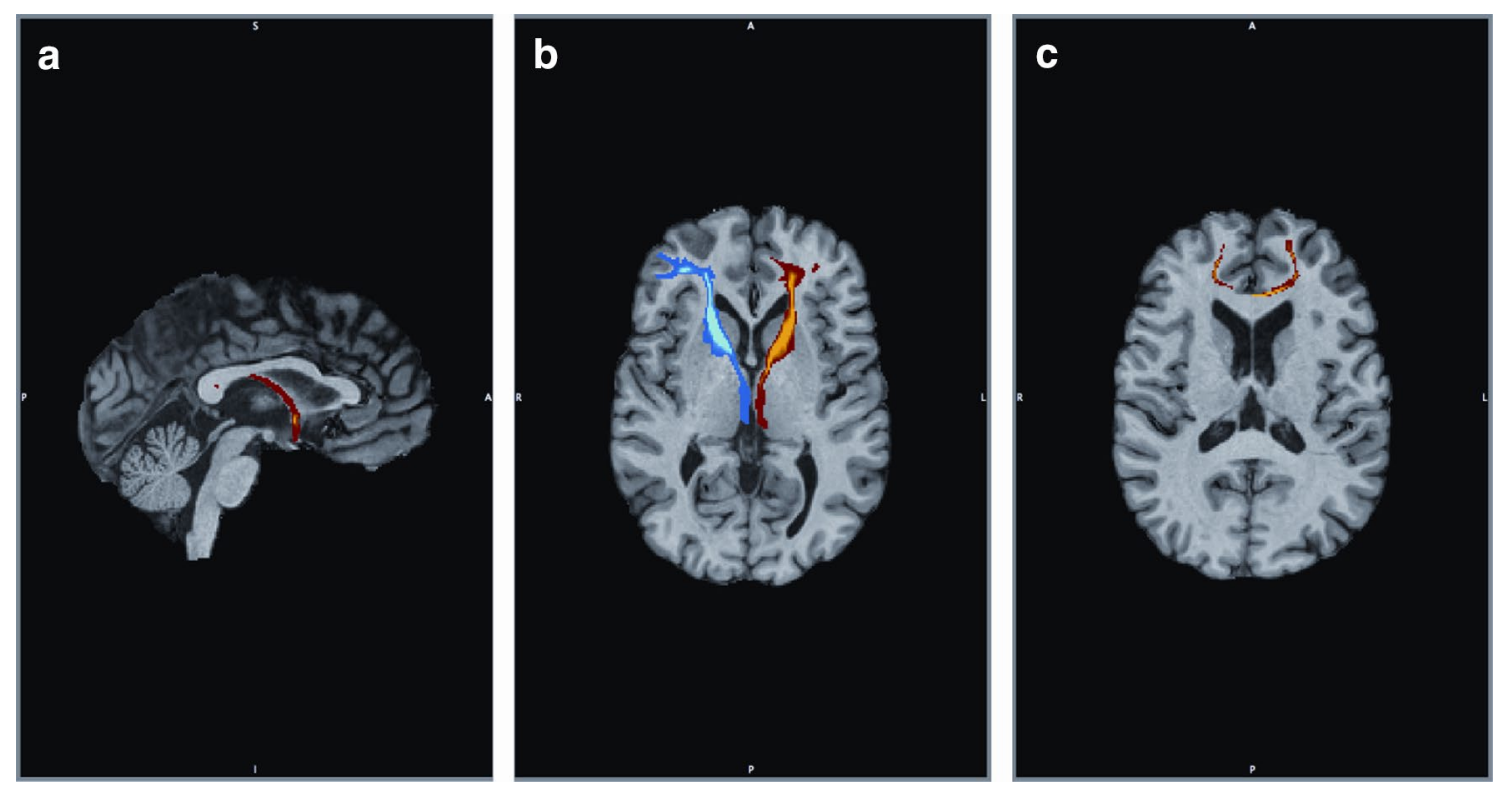

Fig. 1 Regions of interest include white matter pathways in the forebrain that are important in neurocognitive function and known to be damaged by HIV infection or psychostimulant use. Pathways include the $\mathbf{a}$ anterior commissure (sagittal view), b left (blue) and right (red) anterior limbs of the internal capsule (axial view) and c corpus callosum genu (axial view) 
Table 7 Comparison of neurocognitive data between groups

\begin{tabular}{|c|c|c|c|c|}
\hline Test-variable & Controls $(n=22)$ & Patients $(n=21)$ & Test statistic & Effect size $(d)$ \\
\hline TMT trail A (s) & $31.05 \pm 1.22$ & $33.81 \pm 2.46$ & -0.74 & -0.23 \\
\hline TMT trail B $(s)^{b}$ & $66.77 \pm 4.70$ & $101.29 \pm 10.30$ & $147.0(-2.04)^{*}$ & -0.65 \\
\hline Grooved pegboard dominant hand (s) & $65.86 \pm 1.95$ & $95.05 \pm 5.49$ & $-3.96^{* *}$ & -1.23 \\
\hline Grooved pegboard non-dominant hand (s) & $71.05 \pm 2.03$ & $90.35^{\mathrm{a}} \pm 4.05$ & $-3.80^{* *}$ & -1.21 \\
\hline RVP $A^{\prime}$ & $0.89 \pm 0.01$ & $0.86^{\mathrm{a}} \pm 0.01$ & -1.84 & -0.56 \\
\hline CVLT-II total recall & $45.86 \pm 1.98$ & $34.33 \pm 2.47$ & $-2.37^{*}$ & -0.72 \\
\hline CVLT-II short delay free recall & $10.23 \pm 0.74$ & $7.00 \pm 0.67$ & $-2.13^{*}$ & -0.65 \\
\hline CVLT-II long delay free recall & $10.45 \pm 0.61$ & $7.48 \pm 0.79$ & -1.67 & -0.51 \\
\hline CVLT-II recognition discriminability & $3.04 \pm 0.19$ & $2.47 \pm 0.17$ & -1.30 & -0.40 \\
\hline IED EDS errors ${ }^{b}$ & $9.55 \pm 2.16$ & $17.10 \pm 2.40$ & $168.0(-1.53)$ & -0.61 \\
\hline IED Pre-EDS errors ${ }^{b}$ & $21.41 \pm 4.34$ & $43.86 \pm 7.43$ & $191.0(-0.972)$ & -0.68 \\
\hline
\end{tabular}

Numbers indicate raw scores of group mean \pm SEM with no mathematical transformations (lower scores represent better performance on variables measured in seconds or errors)

Significant difference between groups ${ }^{*} p<0.05,{ }^{* *} p<0.01$

TMT trail making test, RVP rapid visual information processing, CVLT California verbal learning test, IED intra/extra dimensional shift

${ }^{\mathrm{a}} \mathrm{n}=20$; test statistic $=t$ value from independent $t$-tests or ${ }^{\mathrm{b}}$ Mann-Whitney $\mathrm{U}(\mathrm{z})$ value from the non-parametric Mann-Whitney $\mathrm{U}$ test for non-normal data

Table 8 Associations between FA values and cognitive measures

\begin{tabular}{|c|c|c|c|c|c|}
\hline Cognitive domain & Measure & AC & LALIC & CC genu & RALIC \\
\hline Visual scanning speed & TMT trails A & -0.051 & -0.288 & -0.157 & -0.114 \\
\hline Cognitive set-shifting & TMT trails B & -0.274 & $-0.409^{* *}$ & -0.289 & -0.182 \\
\hline Fine motor speed & GP-DH & $-0.338^{*}$ & $-0.468^{* *}$ & $-0.475^{* *}$ & $-0.384^{*}$ \\
\hline Fine motor speed & GP-NDH & -0.145 & $-0.465^{* *}$ & $-0.410^{* *}$ & $-0.318^{*}$ \\
\hline Sustained attention & RVP A' & $0.364^{*}$ & $0.403^{*}$ & $0.335^{*}$ & 0.094 \\
\hline Verbal learning & CVLT-II total recall & 0.235 & $0.419^{* *}$ & 0.206 & $0.343^{*}$ \\
\hline Immediate recall & CVLT-II SDFR & 0.234 & $0.376^{*}$ & 0.065 & 0.242 \\
\hline Delayed recall & CVLT-II LDFR & 0.222 & $0.416^{* *}$ & 0.098 & 0.184 \\
\hline Verbal recognition & CVLT-II recognition & 0.055 & 0.247 & 0.086 & 0.229 \\
\hline Concept shifting & IED EDS errors & -0.122 & -0.053 & -0.280 & 0.052 \\
\hline Concept formation & IED Pre-EDS errors & -0.080 & -0.089 & $-0.317^{*}$ & -0.003 \\
\hline
\end{tabular}

Numbers represent Pearson correlations between cognitive scores and FA values

Significant correlation ${ }^{*} p<0.05,{ }^{* *} p<0.01$

$A C$ anterior commissure, $L A L I C$ left anterior limb of the internal capsule, CC corpus callosum, RALIC right anterior limb of the internal capsule, TMT trail making test, GP grooved pegboard, $D H$ dominant hand, NDH non-dominant hand, RVP rapid visual information processing, CVLT-II California verbal learning test-II, SDFR shortdelay free recall, LDFR long-delay free recall, IED intra-extra dimensional shift, EDS extradimensional

For the right anterior limb of the internal capsule, FA values correlated negatively with both the dominant $(r=-0.384, p=0.014)$ and non-dominant $(r=-0.318$, $p=0.046)$ hand on the grooved pegboard task, reflecting slower fine motor speed and dexterity. Also, as FA scores increased, verbal learning performance was higher (CVLT total recall; $r=0.343, p=0.03$ ).

For the corpus callosum genu, FA values correlated negatively with both the dominant $(r=-0.475$, $p=0.002)$ and non-dominant $(r=-0.410, p=0.009)$ hand on the grooved pegboard task. Higher FA values predicted better sustained attention (RVP A'; $r=0.335$, $p=0.037)$. Finally, there was a negative correlation between FA values and the IED pre-EDS errors score $(r=-0.317, p=0.046)$, reflecting poorer concept formation.

\section{Discussion}

To our knowledge, this is the first study to examine cognitive function and white matter integrity in subjects with a history of heavy psychostimulant use and comorbid HIV infection, compared to healthy, matched control 
subjects. The main findings of the present study are that the patient group exhibited significantly lower white matter integrity, indicated by decreased FA values, in the four important white matter tracts of the anterior commissure, left and right anterior limb of the internal capsule, and the genu of the corpus callosum. With the exception of the anterior commissure, all tracts also showed a significant increase in $M D$ and $R D$, suggesting that increases in axonal membrane permeability, for example by processes such as demyelination, may underlie the observed decrease in FA values. The patient group also displayed widespread neurocognitive impairment, which was significant in tasks that assess cognitive set-shifting, fine motor speed and verbal memory.

All subjects were recruited from the urban setting of the Downtown Eastside of Vancouver, which represents one of the poorest neighborhoods in Canada, with high rates of drug use, poverty, infectious disease and crime [31]. The mean age of the patient group was 37.5 years and length of HIV infection was 8.7 years. A majority of the patient group completed blood work and exhibited laboratory changes consistent with the literature on HIV [32], including decreased total white blood cell counts, decreased CD4 cell counts (immunodeficiency), increased CD8 cell counts (immunosuppression) and a lower $C D 4: C D 8$ ratio. While laboratory values in the patient group were lower than controls, most absolute values were close to accepted norms (http://aids.gov/ index.html), suggesting that most subjects in the patient group were responding to treatment for HIV (although viral loads were not measured). Drug use was assessed over the 30 days prior to the interview. High rates of psychostimulant use were evident in all subjects in the patient group, which included powder cocaine, crack cocaine and amphetamines. Heroin and cannabis use were also common, indicating that drug use in this population is heterogeneous, and is consistent with simultaneous polysubstance use in an urban setting $[33,34]$. The overall picture of the patient population is therefore that of individuals struggling not only with serious drug use and HIV infection, but potentially a host of additional medical co-morbidities. It is noteworthy that there was a significantly greater proportion of the control group that consumed alcohol than the patient group. Absolute amounts of alcohol consumed over the prior 30 days were not excessive in the control group ( $4.6 \pm 5.7$ units) so it seems unlikely that this could account for group differences in FA values, but this requires further verification.

The novel observation that subjects in the patient group had decreased white matter integrity in the four different forebrain pathways adds to our knowledge of the deleterious effects of comorbid HIV infection in heavy psychostimulant users on white matter in the brain [35].
Previous DTI studies in HIV positive subjects reported either a decrease in FA values [36] or no difference from controls [23, 37] in the genu of the corpus callosum, although [38] noted lower FA values only in HIV positive subjects with concurrent alcoholism. Other studies have reported decreases in FA values for the entire corpus callosum $[21,39]$, whereas the present study focused on a specific sub-region of this tract. Previous studies have not observed significant decreases in FA values of the anterior internal capsule in HIV positive subjects compared to controls [39-42], although [22] noted decreased FA values in the right posterior limb of the internal capsule. As such, our study represents the first evidence that the bilateral internal capsule pathways are affected in subjects with HIV infection. We are not aware of any studies that have measured FA values of the anterior commissure in HIV positive subjects.

The effects of psychostimulant drugs on white matter integrity have been the focus of several previous studies. The FA values in the genu of the corpus callosum were either decreased $[12,43]$ or not different $[8,44]$ from controls in cocaine users, while FA values were globally decreased compared to controls in current or former methamphetamine users $[10,11,45]$. We are not aware of prior reports of psychostimulant use on FA values for either the internal capsule or the anterior commissure. In this regard, the current observations are consistent with previous changes reported for the genu of the corpus callosum, and suggest that additional frontotemporal white matter pathways that control neurocognitive processes may be affected by comorbid HIV infection in heavy psychostimulant users.

In the present study, the patient group exhibited substantially lower performance across multiple cognitive domains compared to controls, which likely reflects in part the effects of HIV infection. While there is substantial variability in neurocognitive impairment in patients with HIV, deficits are commonly detected in the areas of speed of information processing [46], fine motor speed and dexterity [47], aspects of learning and memory (i.e., prospective memory, retrieval, etc.) [48] and multiple domains of executive functioning (i.e., mental flexibility, planning, etc.) [49]. Such deficits may be present even when antiviral medication is effective in controlling viral load [50]. Psychostimulant drugs, with extended use, can also significantly impair cognition [3]. Previous deficits in psychostimulant users have been reported with the same cognitive tasks that we used, including the Trail Making Test [51], grooved pegboard [52], CVLT [53], and CANTAB IED task [54].

Importantly, white matter integrity for the four tracts in the present study was significantly correlated with cognitive performance, indicating that decreased FA 
values and consequent loss of white matter integrity in the patient group may represent a physiological substrate for cognitive impairment in this population. Exploratory analyses suggested that all four tracts were each correlated with performance on multiple tasks, and significant correlations were consistent with the known neuroanatomy of specific tests.

Several previous studies have examined the impact of comorbid HIV infection and stimulant use on the brain with alternate MRI techniques. HIV positive cocaine users displayed impaired brain activation in an fMRI study with a delay discounting task [55]. Chang et al. [56] noted that the effects of HIV infection and chronic methamphetamine use were additive when they examined changes in brain metabolites in frontal white matter with MR spectroscopy, indicating that combined psychostimulant drug use and infection caused greater white matter damage. However, [57] noted that effects of both HIV infection and methamphetamine use were not additive in altering grey matter regional volumes, and in some basal ganglia sub-regions the two factors actually opposed each other. These two latter imaging studies suggest that white matter in the brain may be particularly vulnerable to additive effects of psychostimulant use and HIV infection. In the present study, the decreases in white matter integrity in the patient group included regions (left and right anterior limbs of the internal capsule, anterior commissure) not previously reported to be affected in HIV positive subjects without a confirmed history of psychostimulant abuse.

A potential limitation of this study is the absence of control groups that included recent psychostimulant users without HIV infection, or HIV positive subjects without psychostimulant use. This would have better enabled the study to demonstrate unambiguous effects of the drugs, or HIV, or an additive effect of both on the brain. However, the current patient group represents a marginalized population that is commonly encountered in urban settings characterized by high rates of poverty and antisocial behaviors such as crime [24, 33], and where drug use and HIV infection co-occur with extensive other medical comorbidities to affect brain function and structure. Potential comparison groups of HIV positive subjects without drug use, or psychostimulant users without infection (which would reflect different patterns of drug use) would likely represent fundamentally different populations from our study population, living under different and less challenging conditions. Parceling out the individual effects of HIV infection or psychostimulant use therefore presents a significant challenge, as it would be necessary in this population to control for the many other medical and environmental comorbidities that may be interacting to affect general physical health and the brain [25].

\section{Conclusions}

In summary, the present study is the first report of white matter integrity, measured by DTI, in psychostimulant users with comorbid HIV infection. Four main frontotemporal white matter pathways were affected in this group, reflected by decreased FA values. Compared to controls, psychostimulant users with HIV infection displayed broad cognitive impairment, which significantly correlated with white matter integrity. Further study is required to better understand the influence of additional medical comorbidities, resulting largely from drug use, on white matter structure and cognition.

\section{Abbreviations}

CANTAB: Cambridge neuropsychological test automated battery; CBC: complete blood count; CVLT-II: California verbal learning test II; DTI: diffusion tensor imaging; FA: fractional anisotropy; HIV: human immunodeficiency virus; IED: intra/extra dimensional shift; MRI: magnetic resonance imaging; NAART: North American adult reading test; ROI: region of interest; RVP: rapid visual information processing; TMT: trail making test.

\section{Authors' contributions}

VMT drafted the manuscript. DJL was responsible for MRI protocols. CJG was responsible for neurocognitive testing and data analysis. WJP helped design and conduct physical health assessments. TW assisted with analysis of MRI data. RMP analyzed clinical pharmacology. FV-R, WJ and GWM helped design and conduct psychiatric assessments. TL assisted with interpretation of drugdependence data. HNB and AA assisted with analysis of drug-dependence and physical health data. WGH assisted with study design. AMB conceived of the study and was primarily responsible for study design. All authors read and approved the final manuscript.

\section{Author details}

${ }^{1}$ Department of Psychiatry, University of British Columbia, 2255 Wesbrook Mall, Vancouver V6T2A1, Canada. ${ }^{2}$ Department of Radiology, University of British Columbia, 3350-950 W 10th Avenue, Vancouver V5Z1M9, Canada. ${ }^{3}$ British Columbia Mental Health \& Addictions Research Institute, 938 W 28th Avenue, Vancouver V5Z4H4, Canada. ${ }^{4}$ Department of Psychology, Simon Fraser University, 8888 University Drive, Burnaby V5A1S6, Canada. ${ }^{5}$ Département de Psychologie, Université de Montréal, Montreal, QC, Canada. ${ }^{6}$ Department of Pharmacology, University of British Columbia, 2176 Health Sciences Mall, Vancouver, BCV6T1Z3, Canada.

\section{Acknowledgements}

Funding for this study was provided by a Canadian Institutes of Health Research (ClHR) Seed Grant to Dr. Barr. ClHR had no further role in the study. We acknowledge the assistance of Dr. Jocelyn S Lapointe in reviewing the MRI brain scans.

\section{Compliance with ethical guidelines}

\section{Competing interests}

WGH has received consulting fees or sat on paid advisory boards for: $\mathrm{MDH}$ Consulting, In Silico, Lundbeck and Roche. AMB has received grant funding from Bristol-Myers Squibb Canada. All other authors declare that they have no competing interests.

Received: 14 April 2015 Accepted: 21 September 2015

Published online: 30 September 2015 


\section{References}

1. Degenhardt L, Hall W. Extent of illicit drug use and dependence, and their contribution to the global burden of disease. Lancet. 2012;379(9810):55-70

2. Barr AM, Panenka WJ, Macewan GW, Thornton AE, Lang DJ, Honer WG, et al. The need for speed: an update on methamphetamine addiction. J Psychiatry Neurosci. 2006;31(5):301-13.

3. Panenka WJ, Procyshyn RM, Lecomte T, MacEwan GW, Flynn SW, Honer WG, et al. Methamphetamine use: a comprehensive review of molecular, preclinical and clinical findings. Drug Alcohol Depend. 2013;129(3):167-79.

4. Ersche KD, Williams GB, Robbins TW, Bullmore ET. Meta-analysis of structural brain abnormalities associated with stimulant drug dependence and neuroimaging of addiction vulnerability and resilience. Curr Opin Neurobiol. 2013;23(4):615-24.

5. Alba-Ferrara LM, de Erausquin GA. What does anisotropy measure? Insights from increased and decreased anisotropy in selective fiber tracts in schizophrenia. Front Integr Neurosci. 2013;7:9.

6. Alicata D, Chang L, Cloak C, Abe K, Ernst T. Higher diffusion in striatum and lower fractional anisotropy in white matter of methamphetamine users. Psychiatry Res. 2009;174(1):1-8.

7. Chung A, Lyoo IK, Kim SJ, Hwang J, Bae SC, Sung YH, et al. Decreased frontal white-matter integrity in abstinent methamphetamine abusers. Int J Neuropsychopharmacol. 2007;10(6):765-75.

8. Ma L, Hasan KM, Steinberg JL, Narayana PA, Lane SD, Zuniga EA, et al. Diffusion tensor imaging in cocaine dependence: regional effects of cocaine on corpus callosum and effect of cocaine administration route. Drug Alcohol Depend. 2009;104(3):262-7.

9. Lane SD, Steinberg JL, Ma L, Hasan KM, Kramer LA, Zuniga EA, et al. Diffusion tensor imaging and decision making in cocaine dependence. PLoS One. 2010;5(7):e11591.

10. Kim IS, Kim YT, Song HJ, Lee JJ, Kwon DH, Lee HJ, et al. Reduced corpus callosum white matter microstructural integrity revealed by diffusion tensor eigenvalues in abstinent methamphetamine addicts. Neurotoxicology. 2009;30(2):209-13.

11. Tobias MC, O'Neill J, Hudkins M, Bartzokis G, Dean AC, London ED. Whitematter abnormalities in brain during early abstinence from methamphetamine abuse. Psychopharmacology. 2010;209(1):13-24

12. Moeller FG, Hasan KM, Steinberg JL, Kramer LA, Dougherty DM, Santos RM, et al. Reduced anterior corpus callosum white matter integrity is related to increased impulsivity and reduced discriminability in cocainedependent subjects: diffusion tensor imaging. Neuropsychopharmacology. 2005;30(3):610-7.

13. Colfax G, Shoptaw S. The laterally by the putamen on the amethamphetamine epidemic: implications for HIV prevention and treatment. Curr HIV/ AIDS Rep. 2005;2(4):194-9.

14. Rajasingham R, Mimiaga MJ, White JM, Pinkston MM, Baden RP, Mitty JA. A systematic review of behavioral and treatment outcome studies among HIV-infected men who have sex with men who abuse crystal methamphetamine. AIDS Patient Care STDS. 2012;26(1):36-52.

15. Gongvatana A, Cohen RA, Correia S, Devlin KN, Miles J, Kang H, et al. Clinical contributors to cerebral white matter integrity in HIV-infected individuals. J Neurovirol. 2011;17(5):477-86.

16. Leite SC, Correa DG, Doring TM, Kubo TT, Netto TM, Ferracini R, et al. Diffusion tensor MRI evaluation of the corona radiata, cingulate gyri, and corpus callosum in HIV patients. J Magn Reson Imaging. 2013;38(6):1488-93.

17. Nir TM, Jahanshad N, Busovaca E, Wendelken L, Nicolas K, Thompson PM, et al. Mapping white matter integrity in elderly people with HIV. Hum Brain Mapp. 2013;35:975-92

18. Hoare J, Westgarth-Taylor J, Fouche JP, Spottiswoode B, Paul R, Thomas $K$, et al. A diffusion tensor imaging and neuropsychological study of prospective memory impairment in South African HIV positive individuals. Metab Brain Dis. 2012;27(3):289-97.

19. Zhu T, Zhong J, Hu R, Tivarus M, Ekholm S, Harezlak J, et al. Patterns of white matter injury in HIV infection after partial immune reconstitution: a DTI tract-based spatial statistics study. J Neurovirol. 2013;19(1):10-23.

20. Tozzi V, Balestra P, Bellagamba R, Corpolongo A, Salvatori MF, ViscoComandini $U$, et al. Persistence of neuropsychologic deficits despite long-term highly active antiretroviral therapy in patients with HIV-related neurocognitive impairment: prevalence and risk factors. J Acquir Immune Defic Syndr. 2007;45(2):174-82.
21. Stubbe-Drger B, Deppe M, Mohammadi S, Keller SS, Kugel H, Gregor N, et al. Early microstructural white matter changes in patients with HIV: a diffusion tensor imaging study. BMC Neurol. 2012;12:23.

22. Gongvatana A, Schweinsburg BC, Taylor MJ, Theilmann RJ, Letendre SL, Alhassoon OM, et al. White matter tract injury and cognitive impairment in human immunodeficiency virus-infected individuals. J Neurovirol. 2009;15(2):187-95.

23. Wu Y, Storey P, Cohen BA, Epstein LG, Edelman RR, Ragin AB. Diffusion alterations in corpus callosum of patients with HIV. AJNR Am J Neuroradiol. 2006;27(3):656-60.

24. Vila-Rodriguez F, Panenka WJ, Lang DJ, Thornton AE, Vertinsky T, Wong $\mathrm{H}$, et al. The hotel study: multimorbidity in a community sample living in marginal housing. Am J Psychiatry. 2013;170(12):1413-22.

25. Jones AA, Vila-Rodriguez F, Panenka WJ, Leonova O, Strehlau V, Lang DJ, et al. Personalized risk assessment of drug-related harm is associated with health outcomes. PLoS One. 2013;8(11):e79754.

26. Reuter M, Rosas HD, Fischl B. Highly accurate inverse consistent registration: a robust approach. Neuroimage. 2010;53(4):1181-96.

27. Fray PJ, Robbins TW, Sahakian BJ. Neuropsychiatric applications of CANTAB. Int J Geriatric Psychiatry. 1996;11:329-36.

28. Tabachnick BG, Fidell LS. Using multivariate statistics. 5th ed. Boston: Pearson/Allyn \& Bacon; 2007.

29. Marsden J, Gossop M, Stewart D, Best D, Farrell M, Lehmann P, et al. The Maudsley Addiction Profile (MAP): a brief instrument for assessing treatment outcome. Addiction. 1998;93(12):1857-67.

30. Sheehan DV, Lecrubier Y, Sheehan KH, Amorim P, Janavs J, Weiller E, et al. The Mini-International Neuropsychiatric Interview (M.I.N.I.): the development and validation of a structured diagnostic psychiatric interview for DSM-IV and ICD-10. J Clin Psychiatry. 1998;59(Suppl 20):22-33 (quiz 4-57).

31. Linden IA, Mar MY, Werker GR, Jang K, Krausz M. Research on a vulnerable neighborhood-the vancouver downtown eastside from 2001 to 2011. J Urban Health. 2013;90(3):559-73.

32. Lane HC. Pathogenesis of HIV infection: total CD4+ T-cell pool, immune activation, and inflammation. Top HIV Med. 2010;18(1):2-6.

33. Olthuis JV, Darredeau C, Barrett SP. Substance use initiation: the role of simultaneous polysubstance use. Drug Alcohol Rev. 2013;32(1):67-71.

34. Roy E, Richer I, Arruda N, Vandermeerschen J, Bruneau J. Patterns of cocaine and opioid co-use and polyroutes of administration among street-based cocaine users in Montreal, Canada. Int J Drug Policy. 2013;24(2):142-9.

35. Everall IP, Hansen LA, Masliah E. The shifting patterns of HIV encephalitis neuropathology. Neurotox Res. 2005;8(1-2):51-61.

36. Thurnher MM, Castillo M, Stadler A, Rieger A, Schmid B, Sundgren PC. Diffusion-tensor MR imaging of the brain in human immunodeficiency virus-positive patients. AJNR Am J Neuroradiol. 2005;26(9):2275-81.

37. Chang L, Wong V, Nakama H, Watters M, Ramones D, Miller EN, et al. Greater than age-related changes in brain diffusion of HIV patients after 1 year. J Neuroimmune Pharmacol. 2008;3(4):265-74.

38. Pfefferbaum A, Rosenbloom MJ, Adalsteinsson E, Sullivan EV. Diffusion tensor imaging with quantitative fibre tracking in HIV infection and alcoholism comorbidity: synergistic white matter damage. Brain. 2007;130(Pt 1):48-64.

39. Chen Y, An H, Zhu H, Stone T, Smith JK, Hall C, et al. White matter abnormalities revealed by diffusion tensor imaging in non-demented and demented HIV+ patients. Neuroimage. 2009;47(4):1154-62.

40. Hoare J, Fouche JP, Spottiswoode B, Donald K, Philipps N, Bezuidenhout $\mathrm{H}$, et al. A diffusion tensor imaging and neurocognitive study of HIVpositive children who are HAART-naive "slow progressors". J Neurovirol. 2012;18(3):205-12.

41. Xuan A, Wang GB, Shi DP, Xu JL, Li YL. Initial study of magnetic resonance diffusion tensor imaging in brain white matter of early AIDS patients. Chin Med J (Engl). 2013;126(14):2720-4.

42. Pfefferbaum A, Rosenbloom MJ, Rohlfing T, Kemper CA, Deresinski S, Sullivan EV. Frontostriatal fiber bundle compromise in HIV infection without dementia. Aids. 2009;23(15):1977-85.

43. Bell RP, Foxe JJ, Nierenberg J, Hoptman MJ, Garavan H. Assessing white matter integrity as a function of abstinence duration in former cocainedependent individuals. Drug Alcohol Depend. 2011;114(2-3):159-68. 
44. Romero MJ, Asensio S, Palau C, Sanchez A, Romero FJ. Cocaine addiction: diffusion tensor imaging study of the inferior frontal and anterior cingulate white matter. Psychiatry Res. 2010;181(1):57-63.

45. Salo R, Nordahl TE, Buonocore MH, Natsuaki Y, Waters C, Moore CD, et al. Cognitive control and white matter callosal microstructure in methamphetamine-dependent subjects: a diffusion tensor imaging study. Biol Psychiatry. 2009;65(2):122-8.

46. Carey CL, Woods SP, Rippeth JD, Gonzalez R, Moore DJ, Marcotte TD, et al. Initial validation of a screening battery for the detection of HIV-associated cognitive impairment. Clin Neuropsychol. 2004;18(2):234-48.

47. Chang L, Ernst T, Witt MD, Ames N, Gaiefsky M, Miller E. Relationships among brain metabolites, cognitive function, and viral loads in antiretroviral-naive HIV patients. Neuroimage. 2002;17(3):1638-48.

48. Carey CL, Woods SP, Rippeth JD, Heaton RK, Grant I. Prospective memory in HIV-1 infection. J Clin Exp Neuropsychol. 2006;28(4):536-48.

49. Cattie JE, Doyle K, Weber E, Grant I, Woods SP. Planning deficits in HIVassociated neurocognitive disorders: component processes, cognitive correlates, and implications for everyday functioning. J Clin Exp Neuropsychol. 2012;34(9):906-18.

50. Reger MA, Martin DJ, Cole SL, Strauss G. The relationship between plasma viral load and neuropsychological functioning in HIV-1 infection. Arch Clin Neuropsychol. 2005;20(2):137-43.

51. Madoz-Gurpide A, Blasco-Fontecilla H, Baca-Garcia E, Ochoa-Mangado E. Executive dysfunction in chronic cocaine users: an exploratory study. Drug Alcohol Depend. 2011;117(1):55-8.

52. King G, Alicata D, Cloak C, Chang L. Neuropsychological deficits in adolescent methamphetamine abusers. Psychopharmacology. 2010;212(2):243-9.

53. Reske M, Eidt CA, Delis DC, Paulus MP. Nondependent stimulant users of cocaine and prescription amphetamines show verbal learning and memory deficits. Biol Psychiatry. 2010;68(8):762-9.

54. Ornstein TJ, Iddon JL, Baldacchino AM, Sahakian BJ, London M, Everitt $B J$, et al. Profiles of cognitive dysfunction in chronic amphetamine and heroin abusers. Neuropsychopharmacology. 2000;23(2):113-26.

55. Meade CS, Lowen SB, MacLean RR, Key MD, Lukas SE. fMRI brain activation during a delay discounting task in HIV-positive adults with and without cocaine dependence. Psychiatry Res. 2011;192(3):167-75.

56. Chang L, Ernst T, Speck O, Grob CS. Additive effects of HIV and chronic methamphetamine use on brain metabolite abnormalities. Am J Psychiatry. 2005;162(2):361-9.

57. Jernigan TL, Gamst AC, Archibald SL, Fennema-Notestine C, Mindt MR, Marcotte TD, et al. Effects of methamphetamine dependence and HIV infection on cerebral morphology. Am J Psychiatry. 2005;162(8):1461-72.

58. Lim KO, Wozniak JR, Mueller BA, Franc DT, Specker SM, Rodriguez $C P$, Silverman AB, Rotrosen JP. Brain macrostructural and microstructural abnormalities in cocaine dependence. Drug Alcohol Depend. 2008;92(1):164-72.

59. Bell RP, Foxe JJ, Nierenberg J, Hoptman MJ, Garavan H. Assessing white matter integrity as a function of abstinence duration in former cocainedependent individuals. Drug Alcohol Depend. 2011;114(2):159-68.

60. Ma L, Steinberg JL, Keyser-Marcus L, Ramesh D, Narayana PA, Merchant RE, Moeller FG, Cifu DX. Altered white matter in cocaine-dependent subjects with traumatic brain injury: a diffusion tensor imaging study. Drug Alcohol Depend. 2015;151:128-34.

61. Chung A, Lyoo IK, Kim SJ, Hwang J, Bae SC, Sung YH, Sim ME, Song IC, Kim J, Chang KH, Renshaw PF. Decreased frontal white-matter integrity in abstinent methamphetamine abusers. Int J Neuropsychopharmacol. 2007;10(06):765-75

62. Alicata D, Chang L, Cloak C, Abe K, Ernst T. Higher diffusion in striatum and lower fractional anisotropy in white matter of methamphetamine users. Psychiatry Res Neuroimaging. 2009;174(1):1-8.

63. Lin JC, Jan RK, Kydd RR, Russell BR. Investigating the microstructural and neurochemical environment within the basal ganglia of current methamphetamine abusers. Drug Alcohol Depend. 2015;149:122-7.

64. Pomara N, Crandall DT, Choi SJ, Johnson G, Lim KO. White matter abnormalities in HIV-1 infection: a diffusion tensor imaging study. Psychiatry Res Neuroimaging. 2001;106(1):15-24.

65. Ragin AB, Wu Y, Storey P, Cohen BA, Edelman RR, Epstein LG. Diffusion tensor imaging of subcortical brain injury in patients infected with human immunodeficiency virus. J Neurovirol. 2005;11(3):292-8.
66. Thurnher MM, Castillo M, Stadler A, Rieger A, Schmid B, Sundgren PC. Diffusion-tensor MR imaging of the brain in human immunodeficiency virus-positive patients. Am J Neuroradiol. 2005;26(9):2275-81.

67. Wu Y, Storey P, Cohen BA, Epstein LG, Edelman RR, Ragin AB. Diffusion alterations in corpus callosum of patients with HIV. Am J Neuroradiol. 2006;27(3):656-60.

68. Pfefferbaum A, Rosenbloom MJ, Adalsteinsson E, Sullivan EV. Diffusion tensor imaging with quantitative fibre tracking in HIV infection and alcoholism comorbidity: synergistic white matter damage. Brain. 2007;130(1):48-64.

69. Stebbins GT, Smith CA, Bartt RE, Kessler HA, Adeyemi OM, Martin E, Cox $J$ L, Bammer R, Moseley ME. HIV-associated alterations in normal-appearing white matter: a voxel-wise diffusion tensor imaging study. JAIDS J Acquir Immune Defic Syndr. 2007;46(5):564-73.

70. Schulte T, Müller-Oehring EM, Javitz H, Pfefferbaum A, Sullivan EV. Callosal compromise differentially affects conflict processing and attentional allocation in alcoholism, HIV, and their comorbidity. Brain Imaging Behav. 2008;2(1):27-38.

71. Pfefferbaum A, Rosenbloom MJ, Rohlfing T, Kemper CA, Deresinski S, Sullivan EV. Frontostriatal fiber bundle compromise in HIV infection without dementia. AIDS (London, England). 2009;23(15):1977.

72. Müller-Oehring EM, Schulte T, Rosenbloom MJ, Pfefferbaum A, Sullivan EV. Callosal degradation in HIV-1 infection predicts hierarchical perception: a DTI study. Neuropsychologia. 2010;48(4):1133-43.

73. Hoare J, Fouche J-P, Spottiswoode B, Sorsdahl K, Combrinck M, Stein DJ, Paul RH, Joska JA. White-matter damage in clade C HIV-positive subjects: a diffusion tensor imaging study. J Neuropsychiatry Clin Neurosci. 2011;23(3):308-15.

74. Du H, Wu Y, Ochs R, Edelman RR, Epstein LG, McArthur J, Ragin AB. A comparative evaluation of quantitative neuroimaging measurements of brain status in HIV infection. Psychiatry Res Neuroimaging. 2012;203(1):95-9.

75. Schulte T, Müller-Oehring EM, Sullivan EV, Pfefferbaum A. White matter fiber compromise contributes differentially to attention and emotion processing impairment in alcoholism, HIV-infection, and their comorbidity. Neuropsychologia. 2012;50(12):2812-22.

76. Stubbe-Drger B, Deppe M, Mohammadi S, Keller SS, Kugel H, Gregor N, Evers S, Young P, Ringelstein E-B, Arendt G, Knecht S, Husstedt IW, German Competence Network HIV/AIDS. Early microstructural white matter changes in patients with HIV: a diffusion tensor imaging study. BMC Neurol. 2012;12(1):23

77. Wright P, Heaps J, Shimony JS, Thomas JB, Ances BM. The effects of HIV and combination antiretroviral therapy on white matter integrity. AIDS (London, England). 2012;26(12):1501.

78. Xuan A, Wang GB, Shi DP, Xu JL, Li YL. Initial study of magnetic resonance diffusion tensor imaging in brain white matter of early AIDS patients. Chin Med J. 2013;126(14):2720-4.

79. Kamat R, Brown GG, Bolden K, Fennema-Notestein C, Archibald S, Marcotte TD, Letendre SL, Ellis RJ, Woods SP, Grant I, Heaton RK, the TMARC Group. Apathy is associated with white matter abnormalities in anterior, medial brain regions in persons with HIV infection. J Clin Exp Neuropsychol. 2014;36(8):854-66

80. Nir TM, Jahanshad N, Busovaca E, Wendelken L, Nicolas K, Thompson PM, Valcour VG. Mapping white matter integrity in elderly people with HIV. Hum Brain Mapp. 2014;35(3):975-92.

81. Corrêa DG, Zimmermann N, Doring TM, Wilner NV, Leite SC, Cabral RF, Fonseca RP, Bahia PRV, Gasparetto EL. Diffusion tensor MR imaging of white matter integrity in HIV-positive patients with planning deficit. Neuroradiology. 2015;57(5):475-82.

82. Ragin $A B$, Wu Y, Gao Y, Keating S, Du H, Sammet C, Kettering CS, Epstein LG. Brain alterations within the first 100 days of HIV infection. Ann Clin Transl Neurol. 2015;2(1):12-21.

83. Wright PW, Vaida FF, Fernández RJ, Rutlin J, Price RW, Lee E, Peterson J, Fuchs D, Shimony JS, Robertson KR, Walter R, Meyerhoff DJ, Spudich S, Ances BM. Cerebral white matter integrity during primary HIV infection. AIDS. 2015;29(4):433-42. 